\title{
Demonstration by In Situ Hybridization of the Zonal Modulation of Rat Liver Cytochrome P-450b and P-450e Gene Expression after Phenobarbital
}

\author{
Edward Wojcik, Caroline Dvorak, Jose Chianale, Peter G. Traber, David Keren, and Jorge J. Gumucio \\ Veterans Administration Medical Center, The University of Michigan School of Medicine, Department of Internal Medicine, \\ Section of Gastroenterology and Department of Pathology Ann Arbor, Michigan 48105
}

\begin{abstract}
The various physiological processes that constitute liver function are compartmentalized within the hepatic acinus. The molecular mechanisms modulating the development and maintenance of this hepatocyte heterogeneity have not been defined. The objective of this study was to determine whether transcriptional or posttranscriptional zonal modulation of cytochromes $P-450 b, e$ gene expression was responsible for the heterogeneous induction of the $\mathrm{P}-\mathbf{4 5 0}$ proteins, which is observed after phenobarbital (PB) administration. The exact localization in liver tissue of hepatocytes responding to $P B$ with induction of either $\mathbf{P}-\mathbf{4 5 0} \mathrm{b}, \mathrm{e}$ mRNA or proteins was established by in situ hybridization and by immunofluorescence, respectively. As demonstrated by quantitative assessment of autoradiographs of $\sim 20$ hepatocytes located between a terminal portal venule and a hepatic venule, $P B$ induced the P-450b,e mRNA up to sixfold in the 12-15 hepatocytes located closer to the hepatic venules (zones 2 and 3). In contrast, there was only a twofold induction in the 4-6 hepatocytes surrounding the terminal portal venules (zone 1). Quantitative immunofluorescence using an MAb showed that the acinar distribution of $\mathrm{PB}$-induced $\mathrm{P}-\mathbf{4 5 0} \mathrm{b}, \mathrm{e}$ proteins was similar to that of the mRNA. This combined approach indicated that, most likely, an increased rate of transcription of cytochromes $P-450 b, e$ genes in hepatocytes of zones 2 and 3 concomitantly, with a relative lack of activation, or repression, of these genes in hepatocytes of zone 1 , were responsible for the heterogeneous phenotype observed after PB administration. Therefore, modulation of gene expression among hepatocytes of the liver acinus is one mechanism by which the functional heterogeneity of hepatocytes is attained. Experiments in which the induction of cytochromes $\mathbf{P}-\mathbf{4 5 0 b}$,e genes was studied after administration of either PB or para-hydroxyphenobarbital, a main hepatic metabolite of $P B$, suggested that the species involved in the inductive process is the parent $\mathrm{PB}$ molecule rather than para-hydroxyphenobarbital.
\end{abstract}

\section{Introduction}

The physiological processes of uptake, synthesis, biotransformation, and biliary secretion by the liver occur in functional

Address all correspondence to Dr. Jorge J. Gumucio, Department of Medicine, Veterans Administration Medical Center, 2215 Fuller Road, Ann Arbor, MI 48105.

Received for publication 25 November 1987 and in revised form 8 March 1988.

The Journal of Clinical Investigation, Inc.

Volume 82, August 1988, 658-666 units called liver acini (1). Hepatocytes located near the terminal portal venule, the entry to the acinus, and near the terminal hepatic venule, the acinar exit, contribute to these physiological processes differently (2-4). Nuclear runoff studies performed with nuclei isolated from whole liver (5) have shown that phenobarbital (PB) ${ }^{1}$ induces liver cytochromes $\mathrm{P}-450 \mathrm{~b}, \mathrm{e}$ proteins by increasing the rate of transcription of these genes (6). These data, however, do not explain the finding that this induction of $\mathrm{P}-450 \mathrm{~b}, \mathrm{e}$ proteins occurs mainly in hepatocytes located closest to the hepatic venules $(7,8)$. These observations revealed that regulation of the expression of cytochromes $\mathrm{P}-450 \mathrm{~b}, \mathrm{e}$ genes in liver is a more complex process than previously proposed $(5,6)$. Thus, to account for the heterogeneous phenotype attained after $\mathrm{PB}$, the expression of the cytochromes P-450b,e genes has to be modulated at the acinar level, modulation which may provide insight into the molecular mechanisms involved in the zonal expression of liver function.

Studies using hepatocytes isolated predominantly from the proximal or distal half of the liver acinus suggested that the levels of cytochromes P-450b,e mRNA after administration of $\mathrm{PB}$ to rats, increased predominantly in hepatocyte subpopulations isolated from the distal half of the acinus (9). However, in those preparations, it was difficult to quantitate the degree of contamination with hepatocytes of another zone. Specifically, in those studies (9), the exact localization in tissue of the hepatocytes that contained either the highest or the lowest levels of P-450b,e mRNA could not be defined. To this extent, the molecular mechanisms responsible for the heterogeneous expression of these genes in response to PB remained unknown. Therefore, the main objective of this study was the elucidation of the molecular mechanisms involved in the heterogeneous response of acinar hepatocytes to $\mathrm{PB}$-induction of cytochromes P-450b,e genes.

\section{Methods}

Nonfasted male rats Charles River Breeding Laboratories, Inc., (Wilmington, MA) weighing between 190 and $220 \mathrm{~g}$ were used.

\section{Preparation of the $\left[{ }^{3} \mathrm{H}\right] \mathrm{RNA}$ transcripts}

The R17 cDNA clone used in these experiments recognizes the sequences of both cytochromes P-450b and P-450e mRNAs. For this reason, measurements have been described in the text as "cytochromes P-450b,e mRNA." This clone was a generous gift of Dr. M. Adesnik (New York University). It contains a $1,100 \mathrm{bp}$ cDNA (pBR322) coding for the 211 amino acids of the $3^{\prime}$ carboxyterminal end of a polypeptide corresponding to cytochrome P-450e (10). The cDNA insert was

1. Abbreviations used in this paper: ANOVA, analysis of variance; $\mathrm{HV}$, hepatic venule; $\mathrm{PB}$, phenobarbital; $p \mathrm{OHPB}$, para-hydroxyphenobarbital; THV, terminal hepatic venule; TPV, terminal portalvenule. 
cloned into a Riboprobe Gemini system (Promega Biotec, Madison, WI) using the Pst 1 site. The direction in which the insert was cloned into Riboprobe was assessed by agarose gel electrophoresis after Acc I restriction enzyme analysis. Transcription assays were performed by a modification of a previous method (11) as detailed by Promega Biotec (12) using [ $\left.{ }^{3} \mathrm{H}\right]$ UTP (sp act, $52 \mathrm{Ci} / \mathrm{mmol}$ ), $1 \mu \mathrm{Ci} / \mu \mathrm{l}$ of transcription solution. The labeled RNA transcripts that were generated were treated with DNase I (RQ1; Promega Biotec) and $1 \mathrm{U} / \mu \mathrm{g}$ of DNA template, extracted with phenol:chloroform, precipitated with ethanol, and resuspended in TE buffer ( $10 \mathrm{mM}$ Tris, $1 \mathrm{mM}$ EDTA), pH 8.0. The transcripts were finally passed through a Sephadex G-50 column (Pharmacia Fine Chemicals, Piscataway, NJ).

\section{Northern blot and dot blot analysis}

The time curve of induction of cytochromes P-450b,e mRNA was assessed at $5,12,16$, and $22 \mathrm{~h}$ after a single dose of PB. RNA was extracted at each time interval (13) and the size of the mRNA that hybridized to ${ }^{32} \mathrm{P}-\mathrm{RNA}$ transcripts $\left(\left[{ }^{32} \mathrm{P}\right] \mathrm{UTP}\right.$ was used in these experiments) was assessed by Northern blot analysis (9). Dot blot hybridizations with the same ${ }^{32}$ P-RNA probe were performed according to $\mathrm{Pa}$ pavasiliou et al. (14).

\section{In situ hybridization}

\section{PREPARATION OF LIVER SECTIONS}

Rats received a single injection of $\mathrm{PB}(80 \mathrm{mg} / \mathrm{kg}$, i.p. $), 16 \mathrm{~h}$ before the experiments. Uninduced controls received an equivalent volume of $0.15 \mathrm{M} \mathrm{NaCl}$. Rats were anesthetized with ether and the liver perfused in situ with well oxygenated $0.02 \mathrm{M} \mathrm{PBS}, \mathrm{pH} 7.5$, osmolality 300 mosmol/liter at $4^{\circ} \mathrm{C}$, as previously performed in this laboratory (15). After the liver was clear of blood, the perfusate was changed to ice-cold 4\% (wt:vol) paraformaldehyde in $0.1 \mathrm{M}$ sodium phosphate buffer, $\mathrm{pH}$ 7.5. Perfusion was performed at a rate of $10 \mathrm{ml} / \mathrm{min}$ for $4 \mathrm{~min}$. The liver was removed, chopped into 3-mm cubes, and post-fixed for $2 \mathrm{~h}$ at $4^{\circ} \mathrm{C}$ in the same paraformaldehyde solution. The tissue was washed overnight in $0.02 \mathrm{M}$ PBS, $15 \%$ (wt:vol) sucrose, $2 \%$ (vol:vol) polyethylene glycol (mol wt, 400$)$ at $4^{\circ} \mathrm{C}$. The tissue was embedded (O. C. T.; Miles Scientific Div., Naperville, IL) and 8- $\mu \mathrm{m}$ cryostat sections were prepared from various liver lobes. Liver sections were placed onto slides that had been treated with a solution containing $50 \mu \mathrm{g} / \mathrm{ml}$ of polylysine in $10 \mathrm{mM}$ Tris, $\mathrm{pH} 8.0$.

\section{HYBRIDIZATION CONDITIONS}

The procedure used was that of Lum (16) with some modifications. Liver sections were rehydrated in diethylpyrocarbonate-treated distilled water for 5 min and immersed in $0.25 \%$ (vol:vol) acetic anhydride in $0.1 \mathrm{M}$ triethanolamine buffer, $\mathrm{pH} 8.0$ for $10 \mathrm{~min}$ at room temperature. Slides were washed in $2 \times$ SSC (standard saline citrate: $0.149 \mathrm{M} \mathrm{NaCl}, 0.0149 \mathrm{M}$ sodium citrate, $\mathrm{pH} 7.0$ ) for $5 \mathrm{~min}$ at room temperature, dehydrated by passing them through increasing concentrations of ethanol, and dried. Hybridization solution consisted of $50 \%$ formamide (vol:vol), $100 \mu \mathrm{g} / \mathrm{ml}$ sonicated salmon sperm DNA, 1 $\mathrm{mg} / \mathrm{ml}$ yeast transfer RNA, $600 \mathrm{mM} \mathrm{NaCl}, 10 \mathrm{mM}$ Tris, 1 mM EDTA, $2 \%$ (wt:vol) dextran sulfate, $\mathrm{pH} 7.5$. The $\left[{ }^{3} \mathrm{H}\right] \mathrm{RNA}$ probe (sp act, $1-2$ $\times 10^{6} \mathrm{cpm} / \mu \mathrm{g}$ RNA) was denatured by boiling for $1 \mathrm{~min}$ and diluted into the hybridization solution $\left(1-2 \times 10^{5} \mathrm{cpm} / \mathrm{slide}\right) .50 \mu \mathrm{l}$ of complete hybridization solution were applied per slide (containing two serial sections) and a coverslip was applied. Hybridization was performed in a humidified chamber at $47^{\circ} \mathrm{C}$ for $16 \mathrm{~h}$. The coverslip was removed and the slides were washed for $2 \mathrm{~h}$ in decreasing concentrations of SSC. Slides were incubated in RNase A $(20 \mu \mathrm{g} / \mathrm{ml}$ in $0.5 \mathrm{M}$ $\mathrm{NaCl}, 10 \mathrm{mM}$ Tris, $\mathrm{pH} 8.0$ ) at $37^{\circ} \mathrm{C}$ for $1 \mathrm{~h}$. The slides were rinsed in distilled water, dried, and immersed in a Kodak NTB-2 emulsion. Slides were exposed for 10-20 d and developed. Sections were stained with Giemsa and photography was performed under dark field.

\section{SPECIFICITY CONTROLS}

RNase-treated liver sections. Some of the serial liver sections were treated with RNase A $(20 \mu \mathrm{g} / \mathrm{ml}$ in $0.5 \mathrm{M} \mathrm{NaCl}, 10 \mathrm{mM}$ Tris, $\mathrm{pH} 8.0$ at $37^{\circ} \mathrm{C}$ for $30 \mathrm{~min}$ ) before hybridization.
Hybridization with noncomplementary $R N A$. Other liver sections were hybridized with $\left[{ }^{3} \mathrm{H}\right] \mathrm{RNA}$ transcripts generated by transcription of the noncomplementary DNA strand of the R17 clone.

\section{Immunofluorescence localization of the cytochromes $P-450 b$, e apoproteins}

Rats were treated with either a single dose of $\mathrm{PB}(80 \mathrm{mg} / \mathrm{kg}$, i.p. $)$ or 0.15 $\mathrm{M} \mathrm{NaCl}$. Previous studies in this laboratory have shown that the maximal induction of total cytochrome P-450 activity, assessed spectrophotometrically, is achieved by $\sim 33 \mathrm{~h}$ after a single dose of $\mathrm{PB}(9)$. Therefore, $33 \mathrm{~h}$ after a single dose of PB, snap-frozen pieces of liver were sectioned at $6 \mu \mathrm{m}$ in a cryostat. Liver sections of various lobes were air dried and treated with mouse MAbs to rat liver cytochrome P-450b,e, that was diluted 1:100 in PBS, pH 7.2. This MAb was a generous gift of Dr. U. Meyer (Basel, Switzerland). The purity and validation of the specificity of this antibody have been reported (17). Since this antibody cannot distinguish between the apoproteins of cytochromes $\mathrm{P}-450 \mathrm{~b}$ and $\mathrm{P}-450 \mathrm{e}$, the data have been expressed here as "cytochromes P-450b,e proteins." After a 30 -min incubation in a moisture chamber, the antibody was rinsed off the slides and the tissue sections were washed five times in PBS. A 1:20 dilution of fluoresceinconjugated goat anti-mouse Ig (Cappel Laboratories, Malvern, PA) was applied to each section. Uninduced control livers were similarly treated. To establish a background, tissue sections were treated with other MAbs raised against proteins not found in the liver (negative controls), followed by incubation with fluorescein conjugates and washes. A coverslip was placed over tissue sections using glycerol/PBS (9:1) mounting media and examined under a fluorescent microscope equipped for epifluorescence (Carl Zeiss, Inc., Thornwood, NY).

\section{Quantitative analysis of in situ hybridization and of immunofluorescence results \\ STATISTICS}

Quantitation of autoradiogram as well as of immunofluorescence were performed at the Image Analysis Laboratory of The University of Michigan (Department of Anatomy and Cell Biology) using an International Imaging Systems model 75 image processor (Milpitas, CA). The processor was connected to a Masscomp MC 500 host computer (Westford, MA). Images were recorded under dark field illumination using a Dage video camera.

Software was developed that allowed us to divide the distance between a terminal portal venule (TPV) and a hepatic venule (HV), representing a hemiacinus, into 10 acinar segments. Each segment encompassed $\sim$ two hepatocytes in length and about three liver plates in width. Since the number of hepatocytes, and thus, the distance between a TPV and an HV, varies, the program always divided this distance into 10 squares in which the relative location of each segment was kept constant. The cell area encompassed in each of these squares was computed.

The video image was converted into a binary image (two colors) during which silver grains were separated from background. Each silver grain comprised a different number of pixels depending on the relative size of a grain or clump of grains. The computer counted the number of pixels. Artefacts created by the histological procedure, i.e., dirt and dust particles of comparable brightness to silver grains, could be manually edited. If $>5 \%$ of any square had to be edited, the program called for rejection of the measurement of that hemiacinus. Results have been recorded as absolute number of pixels as well as percentage of pixels counted in each acinar segment from the total number of pixels in the hemiacinus.

For immunofluorescence measurements, liver sections were analyzed using a Leitz fluorescence microscope equipped for epifluorescence. 20 microscopic fields were oriented from TPV to HV, each divided into 10 squares, and quantitated in an analogous manner to the autoradiographs.

Differences between values (autoradiographs or fluorescence) for each of the ten segments in which the hemiacinus was divided were analyzed using one way analysis of variance (ANOVA). Individual 
means were compared using Tukey's test for multiple comparisons (18). When assessing differences between treated and untreated groups, two-way ANOVA was used and individual means were compared using Tukey's test. A level of significance of $P<0.05$ was chosen.

\section{The role of para-hydroxyphenobarbital pOHPB in cytochrome P-450b,e gene induction}

To assess whether PB or its main hepatic metabolite, $p O H P B$, was responsible for cytochrome $\mathrm{P}-450 \mathrm{~b}, \mathrm{e}$ gene induction, male SpragueDawley rats (180-220 g) were injected with: $0.15 \mathrm{M} \mathrm{NaCl}, 0.2 \mathrm{ml}$, i.p., PB $80 \mathrm{mg} / \mathrm{kg}$, i.p. as a single injection, or 5-ethyl, 5-pOHPB (Sigma Chemical Co., St. Louis, MO). pOHPB was injected as a single intraperitoneal injection of $400 \mathrm{mg} / \mathrm{kg}$ and the liver was removed at 5,16 , and $21 \mathrm{~h}$ under ether anesthesia, or it was injected as three daily doses of $400 \mathrm{mg} / \mathrm{kg}$, i.p. each and the liver removed $16 \mathrm{~h}$ after the last injection. These doses were chosen since previous studies $(19,20)$ have shown that the concentration of $p O H P B$ attained in liver after exogenous administration of this metabolite were higher than the concentrations of $P B$ attained in liver by administration of an inductive dose of PB. Moreover, administration of $p \mathrm{OHPB}$ in these doses has resulted in modifications of microsomal enzymes $(19,20)$. Immediately before injection, pOHPB and PB were dissolved in $0.5 \mathrm{~N} \mathrm{NaOH}$, to which a solution containing 75\% (vol:vol) propylene glycol and 10\% (vol:vol) ethanol was added and its $\mathrm{pH}$ was adjusted to 7.4 with $\mathrm{HCl}$.

RNA was extracted from livers according to Chirgwin et al. (13). Only şamples with a 260/280 absorbance ratio above 1.8 were used. In some experiments, poly $\left(\mathrm{A}^{+}\right)$RNA was isolated from total RNA using poly (U) paper (Hybond -m AP paper; Amersham Corp., Chicago, IL). The levels of cytochromes P-450b,e mRNA after $p$ OHPB administration were measured by quantitative dot blot hybridization $(14,21)$. A Minifold II system and nitrocellulose filters were used. The concentration of the cDNA probe was always in excess while each RNA sample was spotted in six concentrations: $0.5,0.75,1.0,1.5,2.0$, and $2.5 \mu \mathrm{g} / \mathrm{spot}$. This allowed us to assess the linearity of measurements with each sample. An internal standard (PB-induced RNA) was also spotted in six concentrations to account for reproducibility and for differences in efficiency of hybridization. Comparisons between controls, PB, and pOHPB samples were established in the same filter.

The cytochrome $\mathrm{P}-450 \mathrm{~b}$,e probe used in dot blot hybridizations was the cDNA insert isolated from the R17 clone of Adesnik (10) described above. This cDNA insert was labeled with $\left[{ }^{32} \mathrm{P}\right] d \mathrm{ATP}$ (Amersham Corp., sp act, $3,000 \mathrm{Ci} / \mathrm{mmol}$ ) by the oligolabelling method of Feinberg (22) using the large fragment of DNA polymerase I (Klenow fragment).

\section{Results}

\section{PB-induction of cytochromes P-450b,e mRNAs in zonal hepatocytes: in situ hybridization}

\section{QUALITATIVE ASSESSMENT}

$16 \mathrm{~h}$ after a single injection of $\mathrm{PB}$, the changes in the levels of cytochromes P-450b,e mRNA were assessed. Fig. $1 A$ shows a photograph obtained at low magnification in which grains are predominantly present in 12-15 hepatocytes closer to the terminal HV $(H)$. The hepatocytes that immediately surround the two TPV $(P)$ show a much lower number of grains. The distribution of grains in hepatocytes surrounding these acinar landmarks, the TPVs and HVs is shown at a higher magnification in Fig. 1, $B$ and $C$. Numerous silver grains were visible in hepatocytes of zone 3 (Fig. $1 B$ ) while very few were visible in hepatocytes of zone 1 (Fig. $1 C$ ). Few grains, denoting background, were visible in the lumen of venules and sinusoids.

Fig. $2 A$, shows the levels of cytochromes P-450b,e mRNA determined in livers of uninduced controls. Fewer grains, apparently distributed homogeneously, were observed. The specificity of these results was tested by hybridizations of the complementary $\left[{ }^{3} \mathrm{H}\right]$ RNA transcripts with RNase-treated sections (livers induced $16 \mathrm{~h}$ earlier with PB). As shown in Fig. $2 \mathrm{~B}$, RNase treatment completely abolished hybridization, indicating that the probe was recognizing RNA sequences. To further assess the specificity of these results, $\left[{ }^{3} \mathrm{H}\right] \mathrm{RNA}$ transcripts generated by transcription of the noncomplementary DNA strand of the R17 cDNA rather than complementary RNA transcripts were used in hybridizations. The result was a picture similar to that illustrated in Fig. $2 B$ (results not shown). There was a very low level of grains distributed homogenously, a finding quite different from that of Fig. $1 \mathrm{~A}$. The lack of hybridization of these noncomplementary transcripts with cytochromes P-450b,e mRNA was assessed by Northern blot analysis (results not shown). These two controls established the specificity of the hybridized material. Furthermore, the level of background signal was shown by these experiments to be quite low.

\section{QUANTITATIVE ASSESSMENT}

In situ hybridization. The changes in the levels of cytochromes P-450b,e mRNA after PB, as assessed by in situ hybridization, were quantitated with an image analysis system. In this process, the number of pixels (representing the number and size of silver grains) were counted. Results have been expressed either as percentage of distribution of pixels in each of the 10 acinar segments in which the hemiacinus was divided, or as the absolute number of pixels (in studies in which control and PBtreated livers were assessed in the same experiment). Expression of results as the percentage of distribution of pixels normalized the data for small differences in background between acini.

Fig. $3 \mathrm{~A}$ depicts the percentage of distribution of pixels in uninduced control livers. A homogeneous distribution of grains with a small decrease in grain density in the four hepatocytes closest to the HV was observed.

Fig. $3 B$ illustrates the percentage of distribution of pixels in the 10 acinar segments measured $16 \mathrm{~h}$ after a single dose of PB. There was a progressive increment in the levels of cytochromes P-450b,e mRNA from TPV to HV. Maximal induction was attained in segments 5-9, which corresponded to the 10th-18th hepatocyte away from the TPV. A small decrease in the total number of pixels counted in the two hepatocytes immediately contiguous to the HV was noted.

To assess the validity of the comparisons between segments, the relative cell area of each segment was determined. Fig. $3 C$ shows that the relative cell areas were similar with the exception of the last two segments in which a small decrease in cell area measured was noted. This lower cell area of the two last segments may explain, in part, the small decrease in the number of pixels counted in these segments.

Results of these measurements expressed in absolute values are illustrated in Fig. $3 \mathrm{D}$. It should be noted, that to make the comparison of absolute values valid, in situ hybridization of control and PB-treated livers was performed in the same experiment (that is, the same hybridization solution, hybridization conditions, and labeled probe were used). While there was a twofold increment in the number of pixels counted in the first four hepatocytes, induction of cytochromes P-450b,e mRNA increased by sixfold in hepatocytes 12-18. Again, a 

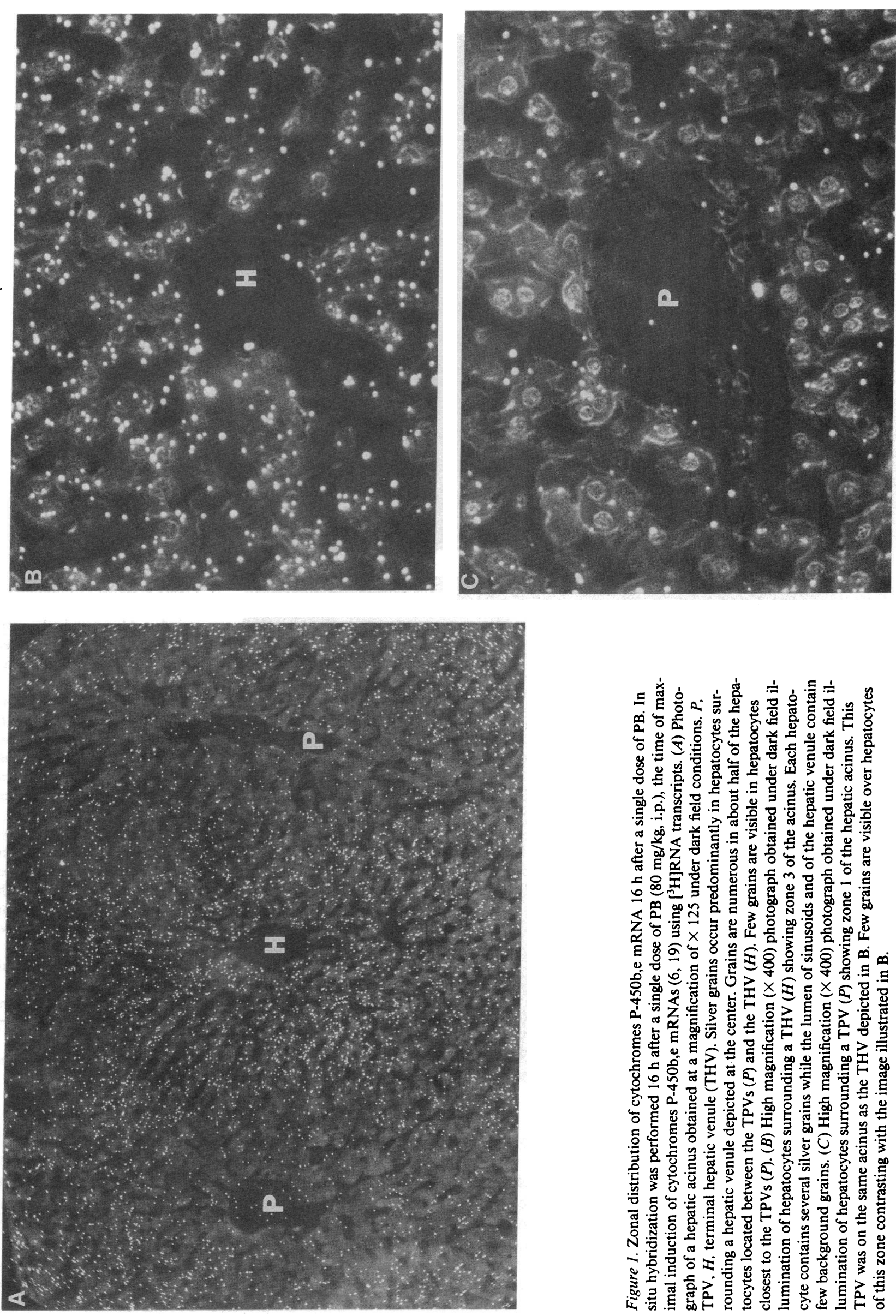

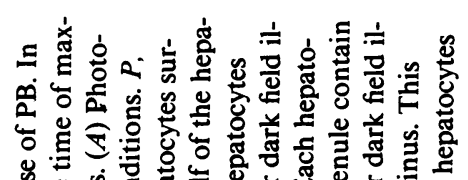

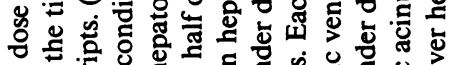
0.0 क力 कि

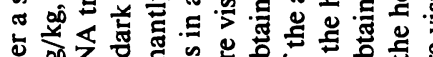

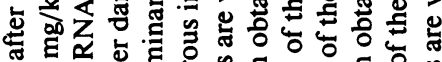

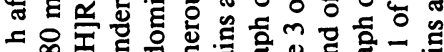

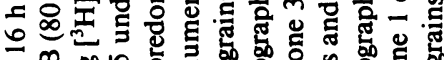

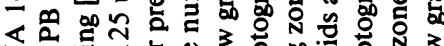

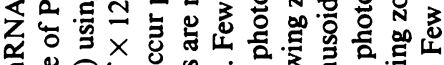

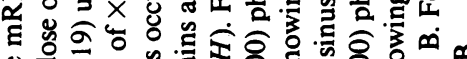
0. 。广.

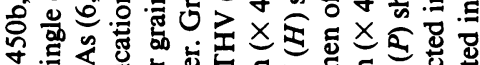

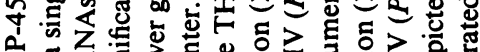

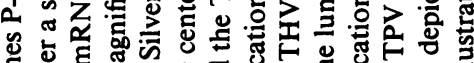

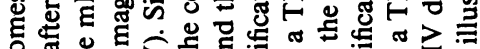

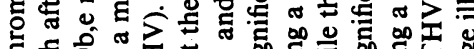

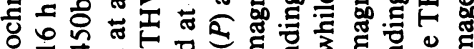
年

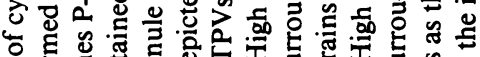

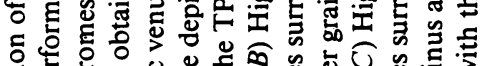
은

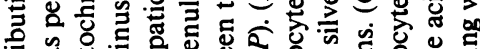

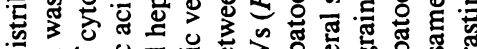

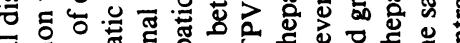

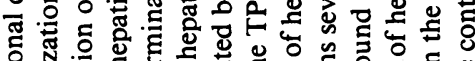
N

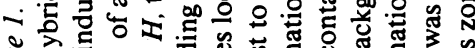

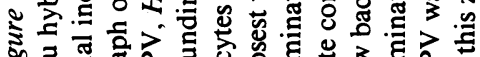

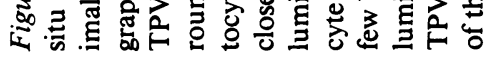



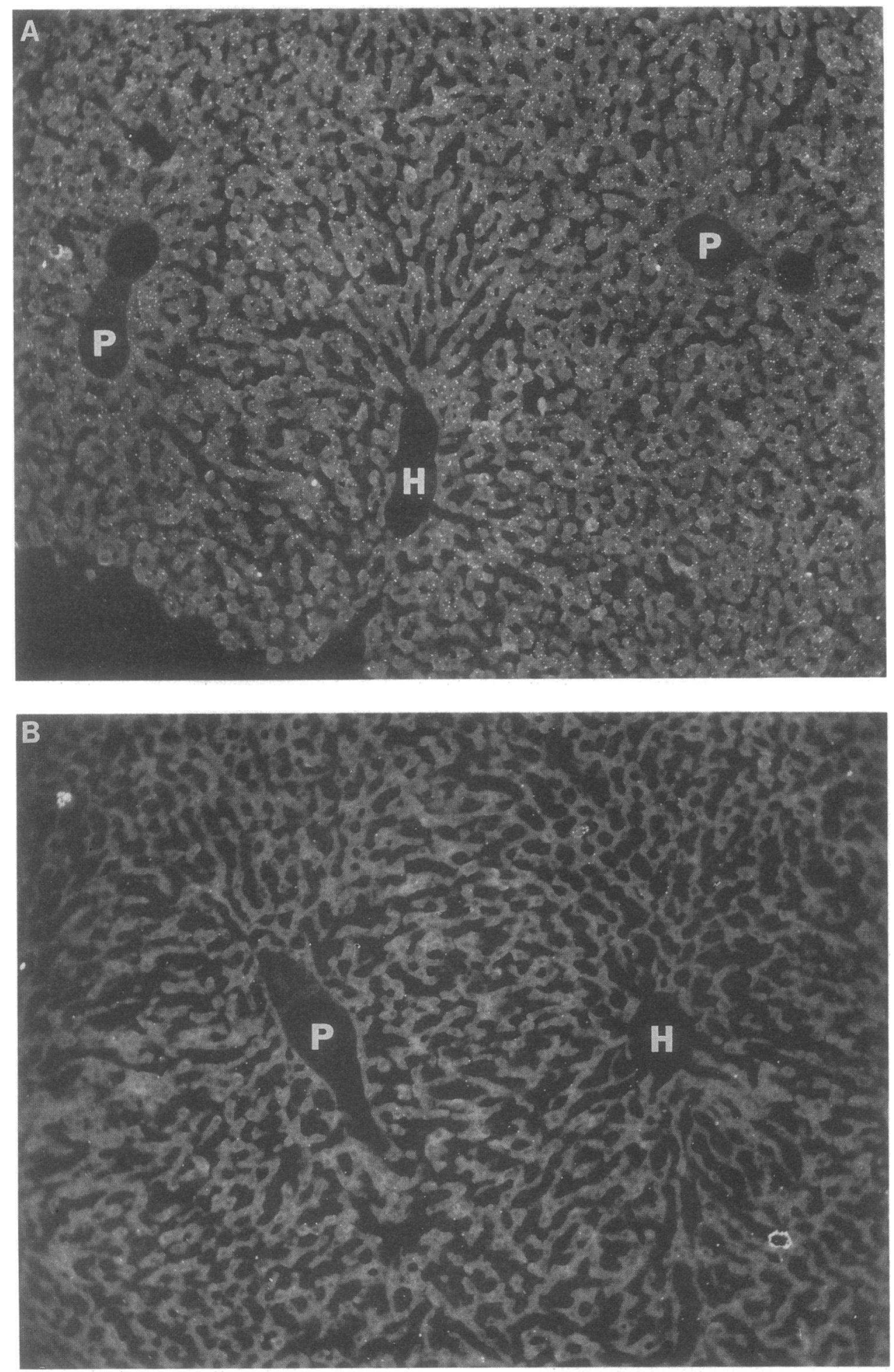

Figure 2. Zonal distribution of cytochromes P-450b,e mRNA in uninduced liver, and other control conditions. $(A)$ Low power $(\times 125)$ dark field photograph of in situ hybridization of cytochromes P-450b,e mRNA in uninduced rat liver. $P$, TPV, $H$, THV. Few silver grains are visible and the distribution throughout the acinus appears uniform. Autoradiography exposure time for all photographs shown as Fig. 2 was 6 wk. (B) In situ hybridization performed in PB-induced rat livers $(16 \mathrm{~h})$ that were treated with RNase A before hybridization with the complementary $\left[{ }^{3} \mathrm{H}\right] \mathrm{RNA}$ transcripts. Liver sections were treated with RNase A $(20 \mu \mathrm{g} / \mathrm{ml})$ for $30 \mathrm{~min}$ at $37^{\circ} \mathrm{C}$ before hybridization. Few silver grains are visible indicating that the complementary transcripts require RNA sequences in hepatocytes for hybridization.

small decrease in pixel counts was visible in hepatocytes immediately surrounding the HV.

Immunofluorescence. The distribution of cytochromes $\mathrm{P}-450 \mathrm{~b}, \mathrm{e}$ apoproteins assessed by immunofluorescence using an MAb was quantitated by the same method used in in situ hybridizations. Fig. 4 shows that, as observed with mRNA, the apoproteins were induced to a small extent in the first six hepatocytes and reached maximal induction in hepatocytes 14-20. Overall, the pattern of induction was similar to that of the P-450b,e mRNA, which indicates that translation of mRNA occurred in all hepatocytes. Given that both methods, in situ hybridization and immunofluorescence, have different sensitivities and resolution, small differences in the relative distribution of grains and fluorescence in any segment are to be expected.

The hepatocytes showing the maximal degree of cytochrome $\mathrm{P}-450 \mathrm{~b}, \mathrm{e}$ mRNA induction also showed maximal induction of the apoproteins. To this extent, there was no 

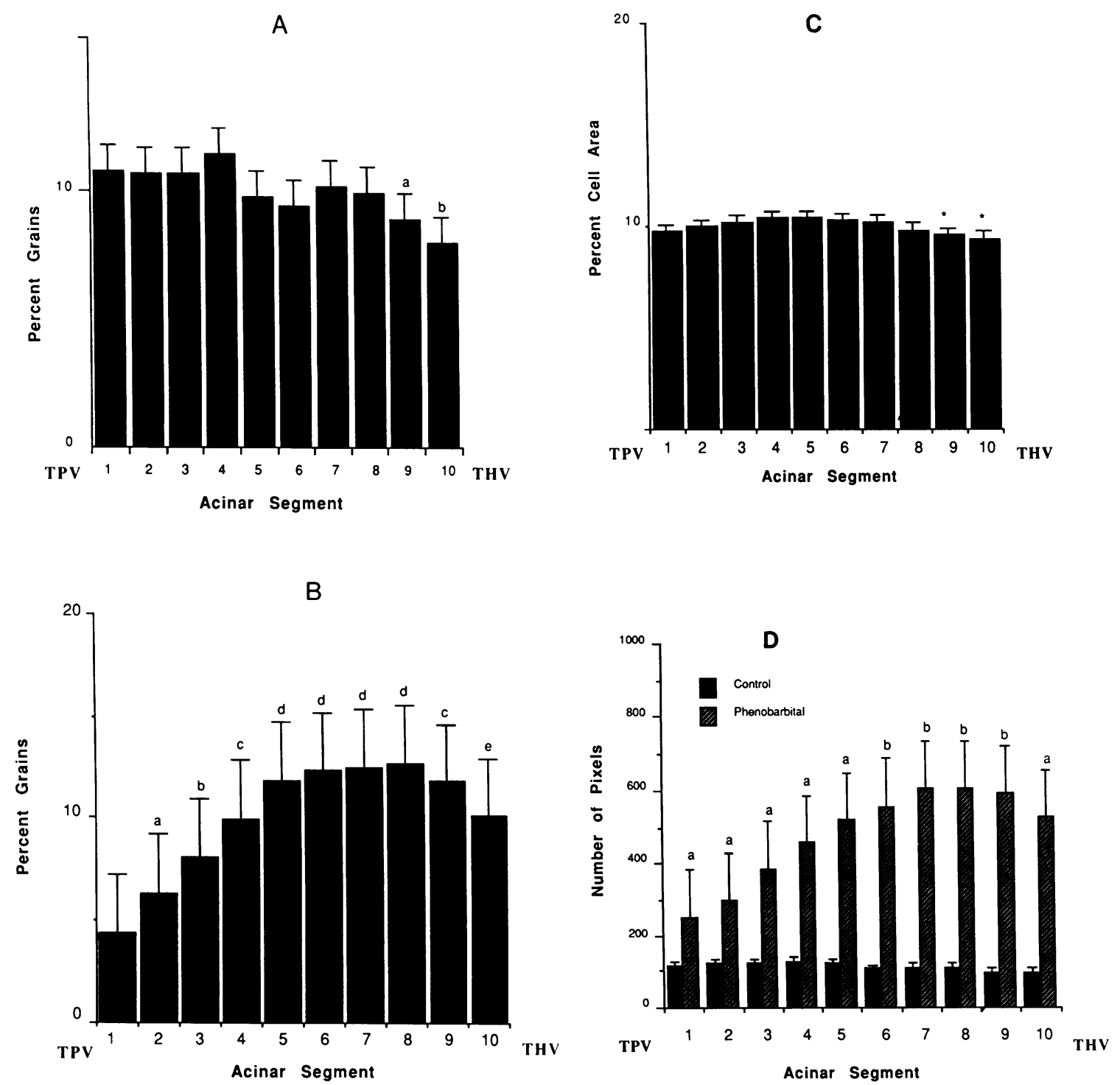

Figure 3. Quantitative assessment of cytochromes P-450b,e mRNA distribution within the hepatic acinus in response to $P B$ assessed by in situ hybridization. Silver grains depicted in the photographs were converted to pixels by the Image Analysis software. The number of pixels on the digitalized image were counted and statistical analysis was performed. The area encompassed between a TPV and a THV (hemiacinus) was divided into 10 segments. The length of each segment comprised about two hepatocytes. The width encompassed hepatocytes from three contiguous plates. $(A)$ Percentage of total pixels distributed in each acinar segment in uninduced controls. Measurements were performed in five uninduced animals. The total number of independent observations was 91 per acinar segment. Mean \pm SD. Significance was assessed by ANOVA, Tukey's test. $A$, less than segments 1, $4(P<0.05) ; B$, less than segments $1-4(P<0.05)$. $(B)$ Percentage of total pixels distributed in each acinar segment $16 \mathrm{~h}$ after PB administration. Measurements were performed in five animals receiving $\mathrm{PB}(80 \mathrm{mg} / \mathrm{kg}$, i.p., $16 \mathrm{~h}$ before the experiment). The total number of independent observations was 117 per acinar segment. Mean \pm SD are illustrated. Significance was assessed by ANOVA, Tukey's test. $a$, Greater than segment 1 and less than segments 3-10. $(P<0.05) ; b$, greater than segments 1,2 and less than 4-10 ( $P$ $<0.05)$; $c$, greater than segments $1-3$ and less than segments 5-9 ( $P$ $<.05)$; $d$, greater than segments $1-3(P<0.01)$ and greater than seg-

ments 4 and $10(P<0.05)$; $e$, less than segments $5-8$ and greater than 1-3 $(P<0.05)$. $(C)$ Cellular area encompassed in each acinar segment as a fraction of the total acinar area. The image analysis software was used to count all pixels in the field of interest excluding the sinusoidal spaces. The data obtained from 36 individual acini are represented. Mean \pm SD. Data was measured in PB-treated $(16 \mathrm{~h})$ livers. Similar data (not shown) was obtained with uninduced controls. *Less than segments 3-7 $(P<0.05)$. (D) Comparison of cytochromes P-450b,e mRNA levels between PB-induced and uninduced controls using absolute values. Statistical analysis of the distribution of cytochromes P-450b,e mRNA in two PB-induced (16 h) rats was compared with that of two uninduced controls. Liver sections obtained from these four animals represented the maximal number of hybridizations that could be handled in one experiment. All samples were treated and hybridized as described under Methods, but here, the same batch of $\left[{ }^{3} \mathrm{H}\right]$ RNA transcripts was used in both groups. Exposure of autoradiograms was the same in both groups. Therefore, the number of pixels counted (corresponding to grains on the digitized image) can be directly compared. Total number of independent observations for uninduced controls was 34, and for PBtreated was 46 . Mean \pm S.D. Significance assessed by two-way ANOVA, Tukey's test. $a$, Greater than control $(P<0.05)$; $b$, greater than control $(P<0.01)$. 


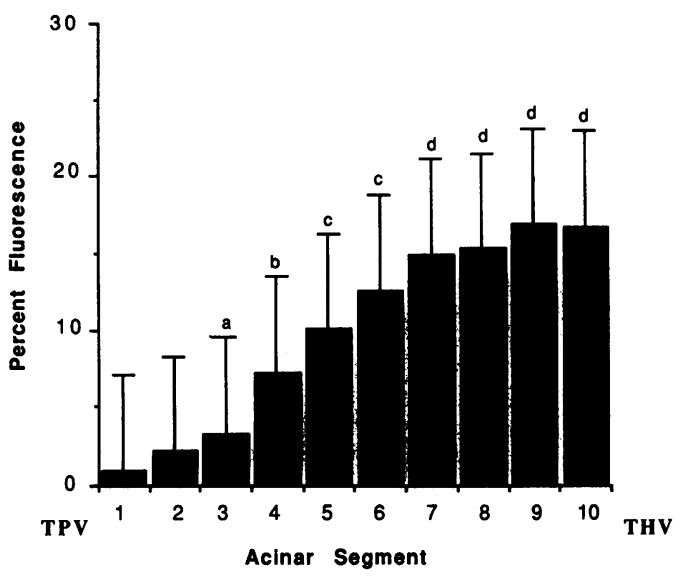

Figure 4. Distribution of cytochromes P-450b,e apoproteins assessed by immunofluorescence. Percentage of fluorescence in each acinar segment was determined using the image analysis software as described in Methods. In these experiments, immunohistochemistry was performed using an MAb that recognizes both cytochrome $\mathrm{P}-450 \mathrm{~b}$ and $\mathrm{e}$ apoproteins. The data represent analysis of 20 individual acini. Mean \pm SD, ANOVA, Tukey's test. $a$, Greater than segments 1,2 and less than 4-10 $(P<0.05) ; b$, greater than segments 1-3 and less than 4-10 $(P<0.05) ; c$, greater than segments $1-4$ and less than 7-10 $(P<0.05)$; $d$, greater than segments $1-6(P<0.05)$.

evidence for translational modulation being the main mechanism responsible for the differential inductive effect of $\mathrm{PB}$ on P-450b,e genes within the hepatic acinus. However, these data cannot rule out small differences in translational efficiency of the P-450b,e mRNA among acinar hepatocytes.

In uninduced control livers, the fluorescent signal was very weak and we were unable to quantitate it. This result was different from data obtained with polyvalent antibodies $(7,8)$ in which fluorescence was detected in control livers. It is possible that polyvalent antibodies may detect other P-450 apoproteins in addition to the $b$ and $e$ isoenzymes, and may thus increase the signal.

The possible inductive role of $p O H P B$, the main hepatic metabolite of $P B$

The time curve of induction of cytochromes $P-450 \mathrm{~b}, \mathrm{e}$ mRNA after single doses of $\mathrm{PB}, \mathrm{pOHPB}$, or $\mathrm{NaCl}$ were compared. Fig. $5 A$ shows that only PB induced these mRNA. Maximal induction with $\mathrm{PB}$ was attained by $\sim 16-24 \mathrm{~h}$, as was previously shown $(5,9)$. To assess whether $p$ OHPB would induce these P-450 genes if administered in various doses, this drug was given as three daily doses of $400 \mathrm{mg} / \mathrm{kg}$, i.p. At these doses, the hepatic concentration of $p O H P B$ has been shown to be higher than the concentration of PB in liver after an inductive dose of PB $(19,20)$. Fig. $5 B$ illustrates that $p O H P B$ was unable to change the levels of cytochromes P-450b,e mRNA. In contrast, three, daily doses of $80 \mathrm{mg} / \mathrm{kg}$ of PB induced the cytochromes P-450b,e mRNA by about sixfold.

\section{Discussion}

This study showed that, after the administration of a single dose of PB, there was induction of cytochromes P-450b,e apoproteins predominantly in hepatocytes located in the half of the acinus closest to the HVs. This result was similar to data previously published using polyclonal antibodies after multi-
A

CYTOCHROME P-450 $(b, e)$ MRNA INDUCTION BY A SINGLE DOSE OF PB OR POH PB

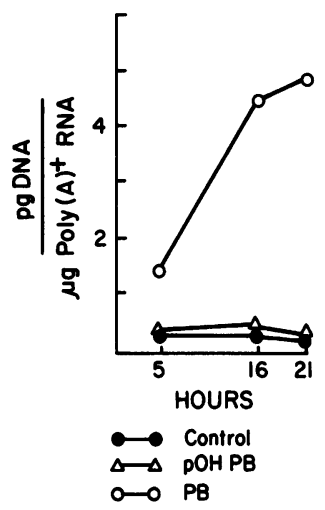

B

CYTOCHROME P-450 $(b, e)$ mRNA INDUCTION BY MULTIPLE DOSES OF PB OR POH PB

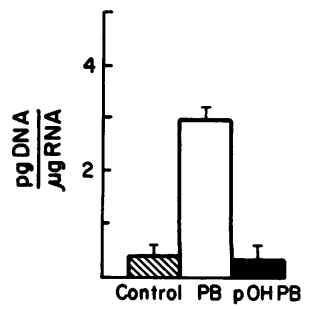

Figure 5. Induction of cytochromes P-450b,e mRNA by $p O H P B$. In these experiments, the levels of cytochrome P-450b,e mRNA were quantitated by dot blot hybridization under conditions in which the cDNA probe was always in excess (14). Therefore, the limiting factor in hybridization was the availability of complementary RNA sequences. The amount of DNA bound reflects the amount of specific cytochrome P-450b,e mRNA. (A) Time course of induction after a single injection of $P B(80 \mathrm{mg} / \mathrm{kg}$, i.p.), pOHPB $(400 \mathrm{mg} / \mathrm{kg}$, i.p.), or $0.15 \mathrm{M} \mathrm{NaCl}$, i.p. (B) Cytochromes P-450b,e mRNA levels after three daily injections of PB (80 mg/kg, i.p.), pOHPB $(400 \mathrm{mg} / \mathrm{kg}$, i.p.), or $0.15 \mathrm{M} \mathrm{NaCl}$, i.p. Means \pm SD.

ple injections of PB $(7,8)$. In this study, the mechanisms responsible for the heterogeneous induction of the apoprotein were studied further by comparing the distribution of the induced P-450b,e apoproteins with the acinar distribution of the induced $\mathrm{P}-450 \mathrm{~b}, \mathrm{e}$ mRNA. A method allowing the quantitative analysis of autoradiographs and fluorescence distribution within the framework of the hepatic acinus was developed. The levels of P-450b,e mRNA (grains-pixels) or apoproteins (fluorescence) were measured in each of 10 segments into which the hemiacinus was divided. Statistical analysis of both autoradiographs and of immunofluorescence slides revealed that there was a low level of induction of both apoproteins and mRNA in the four to six hepatocytes located closest to the TPVs or zone 1. Starting with acinar segment four, which corresponds to about the eighth hepatocyte from the TPV, the inductive response of both apoproteins and mRNA became more apparent. It reached maximal response in the 14th-18th hepatocyte from the TPV. The specificity of these results was assessed in experiments using PB-treated liver sections hybridized with $\left[{ }^{3} \mathrm{H}\right]$ RNA transcripts which were generated by transcription of the noncomplementary R17 cDNA. Only a few grains that were distributed homogeneously along the acinus were observed. Furthermore, when hybridizations were performed with complementary transcripts using liver sections previously treated with RNase, the grains almost completely disappeared.

Since every hepatocyte analyzed expressed both cytochromes P-450b,e apoproteins and mRNA, the major molecular mechanism responsible for the heterogeneous zonal expression after PB is, most likely, a differential regulation in the rate of transcription of these genes along the acinus, rather than major translational differences. Variations in the percent- 
age of distribution of grains and fluorescence in the different acinar segments may suggest minor translational differences within the acinus. However, these small variations should be interpreted cautiously since the sensitivity of in situ hybridization and of the immunofluorescence analysis are not comparable. Therefore, these data are in agreement with data obtained by in vitro transcription assays using nuclei isolated from the whole liver (5).

One alternative explanation for the proposal for differential transcriptional control within the liver acinus, as suggested here, is the possibility that transcription of these genes is induced equally by PB in all hepatocytes but that the mRNA are degraded at different rates. This alternative is unlikely since differences in the half life of cytochromes P-450b,e mRNA by a factor of five or six would have to exist between zonal hepatocytes to account for these observations. The half life of the cytochromes $\mathrm{P}-450 \mathrm{~b}, \mathrm{e}$ mRNA determined in whole liver has been estimated to be $3 \mathrm{~h}$ (23). To our knowledge, there is no example in mammalian tissues of cells within the same organ and of similar origin differing substantially (several hours) in the rate at which these cells degrade a specific mRNA.

A different question is the mechanism triggering the observed differences in the expression of the cytochrome P-450b,e mRNA and the apoproteins among hepatocytes. One possibility is that these results are due to differences in delivery of PB or, alternatively, in the rate at which a metabolite acting as the actual inducer may be generated in the various acinar zones. About $1 \%$ of a PB load is taken up by the liver on a single pass (data not shown). Therefore, PB should be available to all acinar zones. Work performed with bile acids (24), bromosulphthalein (25), fluorescent substances (15), and drugs (26) has shown that all substances tested to date are transported by hepatocytes of every zone. There is no example of a compound that is selectively taken up by hepatocytes of one zone but not by those of another. These data indicated that the possibility that these results were due to $P B$ taken up preferentially by hepatocytes of zones 2 and 3 is highly unlikely. However, the possibility that the intracellular "trapping" of PB may be higher in hepatocytes that show maximal induction is a viable alternative which needs to be assessed by a different approach.

In this study, we tested the possibility that a metabolite of PB, generated in larger amounts in hepatocytes of zones 2 and 3 may be the true inducer. To assess this possibility, $p O H P B$, the main hepatic metabolite of PB, was injected in single as well as multiple doses. Other studies $(19,20)$, have shown that with these doses of $p$ OHPB, the concentration of this metabolite in liver was higher than the concentration of $\mathrm{PB}$ attained by an inductive dose of PB. Moreover, these doses of $p O H P B$ altered the activity of microsomal enzymes $(19,20)$. In contrast to $\mathrm{PB}, \mathrm{pOHPB}$ was unable to induce the cytochromes $\mathrm{P}-450 \mathrm{~b}, \mathrm{e}$ genes. While these data cannot rule out the possibility that minor metabolites may be involved in the inductive process, the lack of induction with $p O H P B$ makes the proposal for differential generation of metabolites unlikely.

Therefore, it is proposed that PB increases the transcription rate of the P-450b,e genes mainly in hepatocytes of zones 2 and 3. Differences in the zonal response to $P B$ are not due to differences in PB uptake or metabolism but to an intrinsic response of zones 2 and 3 to $P B$. This intrinsic response may be secondary to the presence in hepatocytes of transacting factors that regulate the activation of the P-450b,e gene tran- scription in zones 2 and 3 concomitantly with either the absence of these activators, the presence of repressors, or both, in the hepatocytes of zone 1. In support of this proposal, it has been shown that cycloheximide, an inhibitor of protein synthesis, suppresses the increment in transcription rate of liver cytochromes P-450b,e genes after PB, which suggests that active protein synthesis is necessary to attain the inductive response (27). Regardless of the factors responsible for differences in gene expression within the acinus, these data indicate that transcriptional modulation of gene expression is one mechanism by which the heterogeneity of hepatocytes and, therefore, the compartmentation of liver function within the hepatic acinus are maintained.

\section{Acknowledgments}

This study was funded in part by grant AM-32842 from the National Institutes of Health, and by Merit Review Award from the Veterans Administration.

\section{References}

1. Rappaport, A. M. 1973. The microcirculatory hepatic unit. $M i$ crovasc. Res. 6:212-228.

2. Gumucio, J. J., and D. L. Miller. 1982. Functional implications of liver cell heterogeneity. Gastroenterology. 80:393-403.

3. Jungermann, K. 1986. Zonal signal heterogeneity and induction of hepatocyte heterogeneity. In Regulation of Hepatic Metabolism. Thurman, Kauffman, and Jungermann, editors. Plenum Press, New York and London. 445-469.

4. Thurman, R. G., and F. C. Kauffman. 1985. Sublobular compartmentation of pharmacological events (SCOPE): metabolic fluxes in periportal and pericentral regions of the liver lobule. Hepatology (Baltimore). 5:144-151.

5. Hardwick, J. P., F. J. Gonzalez, and C. Kasper. 1983. Transcriptional regulation of rat liver epoxide hydratase, NADPH-cytochrome P-450 oxidoreductase, and cytochrome $\mathrm{P}-450$ b by phenobarbital. J. Biol. Chem. 258:8081-8085.

6. Adesnik, M., S. Bar-Nun, and F. Maschio. 1981. Mechanism of induction of cytochrome P-450 by phenobarbital. J. Biol. Chem. 256:10340-10345.

7. Baron, J., T. T. Kawabata, S. A. Knapp, J. M. Voigt, J. A. Redick, W. B. Jakoby, and F. P. Guengerich. 1984. Intrahepatic distribution of xenobiotic-metabolizing enzymes. In Foreign Compound Metabolism. J. Caldwell, G. D. Paulson, editors. Taylor and Francis, London. 17-36.

8. Ohnishi, K., A. Mishima, and K. Okuda. 1982. Immunofluorescence of phenobarbital-inducible cytochrome P-450 in the hepatic lobule of normal and phenobarbital-treated rats. Hepatology (Baltimore). 2:849-855.

9. Chianale, J., C. Dvorak, and J. J. Gumucio. 1986. Heterogeneous expression of phenobarbital-inducible cytochrome P-450 genes within the hepatic acinus in the rat. Hepatology (Baltimore). 6:945951.

10. Kumar, A., C. Raphael, and M. Adesnik. 1983. Cloned cytochrome P-450 cDNA. J. Biol. Chem. 258:11280-11284.

11. Melton, D. A., P. A. Krieg, and M. R. Rebagliati. 1984. Efficient in vitro synthesis of biologically active RNA and RNA hybridization probes from plasmids containing a bacteriophage sp6 promoter. Nucleic Acids Res. 12:7035-7056.

12. Promega Biotech Manual. 1986. Promega Corp., Madison, WI. $10-12$.

13. Chirgwin, J. M., A. E. Przybyla, R. J. MacDonald, and W. J. Rutter. 1974. Isolation of biologically active ribonucleic acid from sources enriched in ribonuclease. Biochemistry. 18:5294-5299.

14. Papavasiliou, S. S., S. Zmeili, L. Hebron, J. Duncan-Weldon, J. C. Marshall, and T. D. Landefeld. 1986. Alpha and luteinizing hormone beta messenger ribonucleic acid (RNA) of male and female 
rats after castration: quantitation using an optimized RNA dot blot hybridization assay. Endocrinology. 119:691-697.

15. Gumucio, J. J., D. L. Miller, M. D. Krauss, and C. C. Zanolli. 1981. Transport of fluorescent compounds into hepatocytes and the resultant zonal labeling of the hepatic acinus in the rat. Gastroenterology. 80:639-646.

16. Lum, J. B. 1986. Visualization of mRNA transcription of specific genes in human cells and tissues using in situ hybridization. Biotechniques. 4:32-41.

17. Bonkovsky, H. L., H. P. Hauri, U. Marti, R. Gasser, and U. A. Meyer. 1985. Cytochrome P-450 of small intestinal epithelial cells. Immunochemical characterization of increase in cytochrome P-450 caused by phenobarbital. Gastroenterology. 88:458-467.

18. Zar, J. H. 1984. Biostatistical Analysis. 2nd ed. Prentice Hall, Englewood Cliffs, NJ.

19. Cresteil, T., J. L. Mahu, P. M. Dansette, and J. P. Leroux. 1980. In vivo administration of hydroxylated phenobarbital metabolites: effect on rat hepatic cytochromes P-450, epoxide hydrolase and GTPglucuronyltransferase. Biochem. Pharmacol. 29:1127-1133.

20. Cresteil, T., J. L. Mahu, P. Beaune, S. Columelli, and J. P. Leroux. 1981. Comparison of the effects of phenobarbital and its hydroxylated metabolites on drug-metabolizing enzymes during ontogenesis. Pediatr. Pharmacol. 1:331-340.
21. Chianale, J., C. Dvorak, D. L. Farmer, L. Michaels, and J. J. Gumucio. 1988. Cytochrome P-450 gene expression in the functional units of the fetal liver. Hepatology (Baltimore). 8:318-326.

22. Feinberg, A. P., and B. Vogelstein. 1982. Technique for radiolabeling DNA restriction endonuclease fragments to high specific activity. Anal. Biochem. 132:6-13.

23. Ravishankar, H., and G. Padmanaban. 1985. Turnover of messenger RNA, apoprotein and haem of cytochrome P-450 b + e induced by phenobarbitone in rat liver. Biochem. J. 229:73-79.

24. Groothuis, G. M., M. J. Hardonk, K. P. T. Karleman, P. Miervenhuis, and D. K. F. Meijer. 1981. Autoradiographic and kinetic demonstration of acinar heterogeneity of taurocholate transport. Am. J. Physiol. 243:G455-G462.

25. Chen, E. H., J. J. Gumucio, N. H. Ho, and D. L. Gumucio. 1984. Hepatocytes of zones 1 and 3 conjugate sulfobromophthalein with glutathione. Hepatology (Baltimore). 4:467-476.

26. Pang, K. S., and J. A. Terrel. 1981. Retrograde perfusion to probe the heterogeneous distribution of hepatic drug metabolizing enzymes in rats. J. Pharmacol. Exp. Ther. 216:330-346.

27. Chianale, J., L. Mulholland, P. G. Traber, and J. J. Gumucio. 1988. Phenobarbital-induction of cytochromes P-450b,e genes is dependent on protein synthesis. Hepatology (Baltimore). 8:327-331. 